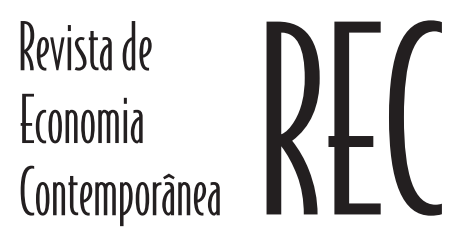

Revista de Economia Contemporânea (2016) 20(1): p. 92-112

(Journal of Contemporary Economics)

ISSN 1980-5527

http://dx.doi.org/10.1590/198055272014

www.ie.ufrj.br/revista

www.scielo.br/rec

\title{
COMMODITY CURRENCIES: UM FENÔMENO REAL NO BRASIL?*
}

\author{
Rodrigo Branco ${ }^{a}$

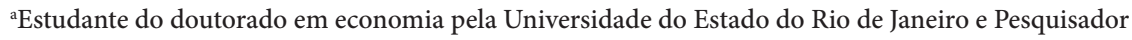 \\ Associado ao Centro de Estudos de Estratégias de Desenvolvimento da Universidade do Estado \\ do Rio de Janeiro (CEDES/UERJ).
}

Artigo recebido em 09/01/2015 e aprovado em 01/02/2016.

\begin{abstract}
RESUMO: Este trabalho tem por objetivo investigar o possível enquadramento que a moeda brasileira, o real, possa ter no modelo de commodity currencies. As evidências encontradas mostram uma correlação significativa da trajetória percorrida pelo real na última década com o esquema de commodity currencies, em que a taxa de câmbio do país tende a acompanhar a evolução dos preços internacionais das commodities, grupo de produtos básicos advindos principalmente dos setores agrícola e mineral.
\end{abstract}

PALAVRAS-CHAVE: commodity currencies; preços de commodities; taxa de câmbio brasileira.

CLASSIFICAÇÃO JEL: F31; F41; E31.

Correspondência para: Rodrigo Branco.

Contato: rsbassociados@gmail.com. 


\title{
COMMODITY CURRENCIES: A REAL PHENOMENON IN BRAZIL?
}

\begin{abstract}
This work aims to investigate the role that the Brazilian currency, Real, may play on the commodity currencies model. The evidences show a significant correlation between the trajectory followed by Real in the last decade and the commodity currencies scheme, where the country's exchange rate tends to follow the evolution of the international commodity prices, understand as a group of products mainly originating from agricultural and mineral sectors.
\end{abstract}

KEYWORDS: commodity currencies; commodity prices; Brazilian exchange rate. 


\section{INTRODUÇÃO — EVOLUÇÃO DOS PREÇOS INTERNACIONAIS DAS COMMODITIES E DO CÂMBIO NO BRASIL}

Com o expressivo aumento nos preços internacionais de alguns produtos básicos produzidos por diferentes países ao longo da última década, principalmente a partir de 2002, o agrupamento de uma série desses bens tem sido motivo de estudo em virtude de sua importância nas trocas internacionais. As commodities, alcunha mais conhecida para tais produtos, têm sido cada vez mais relevantes no comércio externo, em face da crescente demanda mundial por produtos pertencentes, em grande parte, aos setores alimentício e de energia. O objetivo da utilização do termo commodity é diferenciar uma variedade de produtos básicos que são essenciais para o processo produtivo em geral - como petróleo e minérios - e para a alimentação de animais e a humana, bens essenciais à sobrevivência. Além disso, trata-se de bens razoavelmente homogêneos e cujos preços são, em geral, definidos por mercados internacionais organizados, por meio de bolsas de mercadorias.

Tal grupo de produtos tem uma peculiaridade frente aos demais em razão da necessidade de características particulares aos territórios a ser utilizados para sua produção. Por exemplo, no caso dos bens agrícolas, é mister a existência de solo agricultável, clima favorável e grandes extensões de terra que gerem ganhos de escala na produção. No caso do petróleo, deverá haver reservas do hidrocarboneto que permitam a extração economicamente viável do produto, bem como a existência de reservas minerais de larga escala no caso da extração de minério de ferro, cobre ou outros metais de suma importância como insumos nos processos produtivos.

Por sua vez, no que tange à trajetória cambial da moeda brasileira nos últimos anos, a partir da alteração realizada pelo governo brasileiro no regime de câmbio para flutuante em 1999 em face das crises externas sequenciais da Ásia em 1997 e Rússia em $1998^{1}$, o Real tem apresentado sensíveis oscilações diante de crises internas, externas e fatores específicos. Entre os exemplos, estão a crise das empresas "ponto com" nos Estados Unidos em 2001, a crise de confiança em 2002 no período eleitoral no Brasil e a grande crise financeira de 2008, com sua gênese também nos Estados Unidos.

Contudo, o Real manteve uma tendência de valorização ao longo da primeira década dos anos 2000, continuada nos anos subsequentes. Através dessa valorização contínua, com algumas oscilações, surge a argumentação de que tal fenômeno ocorreria em virtude da moeda brasileira estar atrelada aos preços internacionais das commodities, principalmente pelo ganho produtivo que setores da indústria extrativa - no caso

Para maiores detalhes dos reflexos de tais crises no Brasil, ver Averbug e Giambiagi (2000). 
do minério de ferro e do petróleo - e do setor agrícola tiveram ao longo da última década no Brasil, concomitantemente com a elevação dos preços internacionais das commodities, que apresentaram altas consistentes no mesmo período.

Quadros similares já foram observados em diversos países que possuem vantagens comparativas na produção de diferentes commodities, como é o caso de Chile, Austrália e Argentina. Portanto, há indicativos de que o Brasil poderia também estar enquadrado no fenômeno em virtude do ganho recente que a produção de commodities obteve, refletindo principalmente na evolução das exportações brasileiras e alterando de forma sensível o perfil da pauta das vendas ao setor externo.

O objetivo deste trabalho é analisar a possibilidade da existência da correlação entre a valorização do Real e o aumento dos preços das commodities, a fim de verificarmos se a moeda brasileira se enquadra no modelo de commodity currencies, situação já analisada e ratificada para outros países produtores de bens que fazem parte do grupo das commodities. O Brasil, como poderá ser observado nas seções subsequentes a esta introdução, apresenta indícios de que a evolução de preços internacionais de commodities poderia ter influência sobre a trajetória da moeda brasileira em virtude da expansão da produção e, como consequência, da exportação de commodities, com destaque para produtos agrícolas, minério de ferro e petróleo.

Este trabalho se divide em seis seções, além desta introdução. Na seção 2, tratamos da evolução recente das duas principais variáveis de interesse: os preços das commodities e a taxa de câmbio no Brasil, com uma breve revisão do perfil exportador brasileiro desde o início dos anos 2000 até a atualidade, quando a participação das exportações de commodities ganha relevância. $\mathrm{Na}$ seção 3 , analisamos uma das particularidades que a taxa de câmbio brasileira tem em relação aos demais países identificados com o esquema de commodity currencies: a disparidade na evolução entre as taxas de câmbio nominal e real em virtude dos níveis ainda elevados de inflação no país, o que ocasiona diferenças na transmissão ou pass-through para os demais preços da economia, como os das commodities. As seções 4 e 5 tratam do fenômeno de commodity currencies propriamente dito, sua definição e identificação em diversos países através de uma breve revisão da literatura recente sobre o tema. A seção 6 trata do trabalho empírico elaborado a fim de investigar a correlação entre os preços de commodities e a taxa de câmbio no Brasil. A conclusão encerra o artigo com as interpretações dos resultados obtidos.

\section{EVOLUÇÃO DOS PREÇOS DAS COMMODITIES E DO CÂMBIO}

O índice construído pelo Banco Central do Brasil (BCB) para acompanhar a evolução dos preços das commodities, o IC-Br, exibe dois saltos expressivos na primeira década 
dos anos 2000. Entre abril de 2002 e fevereiro de 2003, o índice mais do que dobra, provocando reflexos importantes no setor produtivo de tais bens. Entre 2010 e 2011, há novamente uma elevação expressiva nos preços, tendo ligeiras oscilações desde então.

Gráfico 1 - Evolução do IC-BR

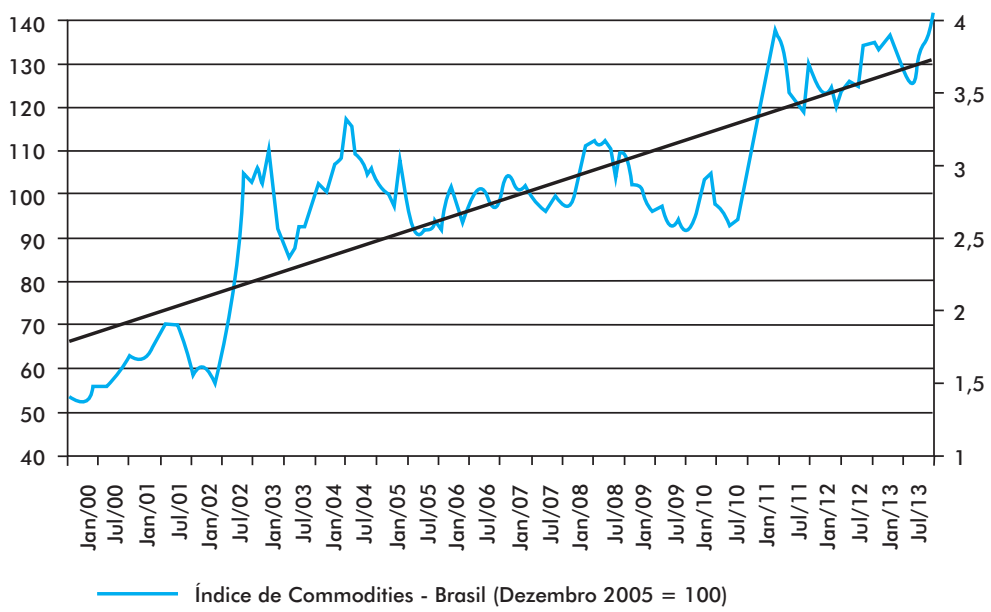

Fonte: $\mathrm{BCB}$.

Os reflexos causados pelo aumento de preços dos produtos que compõem o grupo das commodities têm ganhado importância no Brasil em virtude dos aumentos de produtividade que seus setores produtivos têm alcançado nas últimas décadas, principalmente nos bens advindos do campo. Além disso, mais recentemente, a extração do minério de ferro, bem como a extração de petróleo, tem aumentado sua importância na produção total da indústria extrativa nacional.

Como consequência do sucesso na produção de commodities, com claras vantagens comparativas em relação aos demais players mundiais em alguns produtos que compõem a cesta, a balança comercial brasileira também mostrou importantes alterações em seu perfil (BRANCO, 2013), além de ganhar importância como fator macroeconômico para o crescimento econômico do país.

Por conseguinte, a trajetória observada de valorização do Real poderia estar ligada à evolução positiva dos preços das commodities exportadas pelo país, em virtude da maior participação que a produção de tais bens traria principalmente para a indústria extrativa nacional, bem como ao reflexo positivo que as exportações destes gerariam na balança comercial, e consequentemente nas transações correntes e no balanço de pagamentos do país. Esses reflexos levariam a uma situação externa mais favorável em virtude das maiores divisas recebidas pelo Brasil advindas do exterior com a venda das 
commodities produzidas internamente. Como forma de reequilibrar esse ganho externo adicional, a taxa de câmbio brasileira observaria valorização.

Indícios desse fenômeno podem ser verificados a partir de 2004, quando as evoluções dos preços das commodities no Brasil e do câmbio apresentam trajetórias inversas. Ou seja, enquanto os preços das commodities registram tendência de alta, o Real segue em queda, observando valorização no mesmo período. O gráfico a seguir exibe essas trajetórias de forma mais clara até o fim de 2011.

\section{Gráfico 2 - Evolução do IC-Br e da taxa de câmbio}

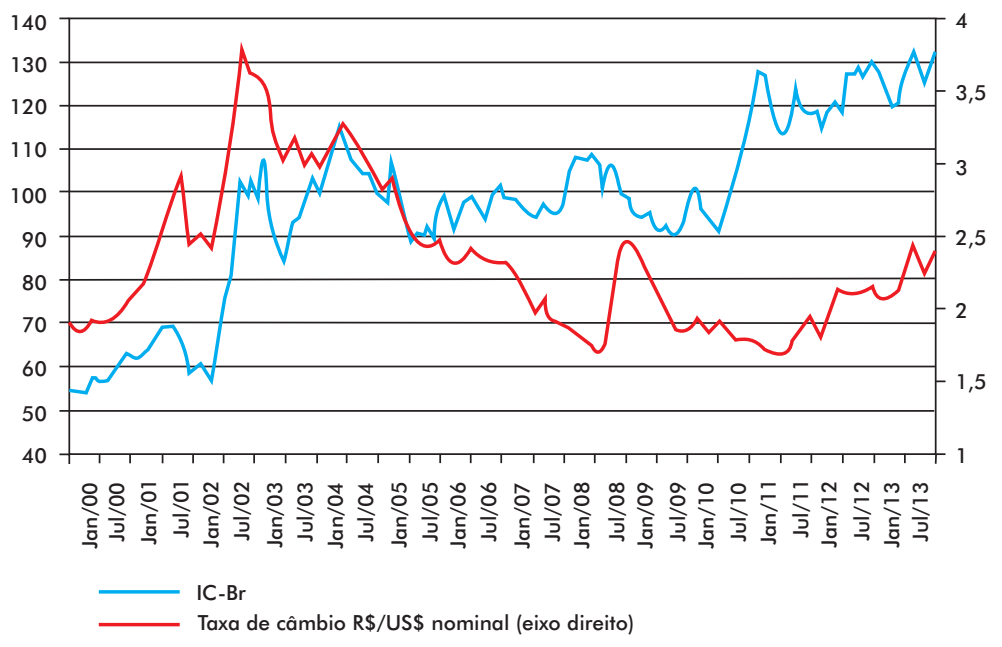

Fonte: $\mathrm{BCB}$.

A possível correlação entre as duas variáveis poderia indicar que a taxa de câmbio no Brasil possa pertencer ao esquema de commodity currencies, em que os preços das commodities exportadas pelo país influenciam sobremaneira a taxa de câmbio. Esse aspecto pode ser reforçado pela alteração no perfil exportador do Brasil no mesmo período, quando as commodities exportadas passam a liderar em termos de participação no total exportado pelo país.

\subsection{EVOLUÇÃO RECENTE DO COMÉRCIO EXTERNO BRASILEIRO}

A participação do grupo das commodities nas exportações brasileiras tem crescido de forma importante e, nos últimos anos, tomou a liderança da pauta exportadora. Entre 2000 e 2013, a participação dos produtos básicos passou de 23,4\% para 48,2\% (acréscimo de 24,8 pontos percentuais em quatorze anos), enquanto os manufaturados vi- 
ram sua participação declinar de $60,7 \%$ para $38,9 \%$ (-21,8 p.p.) no mesmo período. Não podemos menosprezar a importância dessa alteração, dados os reflexos internos na economia brasileira como um todo.

Deve-se destacar ainda que as exportações cresceram no período de 2005 a 2011, lideradas pela alta de preços, que respondeu por 70\% da elevação do montante total exportado. A maior parte dessa alta se deve aos produtos básicos, cujos preços aumentaram quase três vezes mais do que o dos bens manufaturados ${ }^{2}$. Além disso, as diferenças são notáveis também quando se considera apenas a evolução das quantidades exportadas: os básicos acumularam crescimento de 41,1\% entre 2005 e 2011, ao passo que os manufaturados tiveram queda de $14,4 \%$ no mesmo período.

Quadro 1 - Alteração no perfil exportador brasileiro

\begin{tabular}{|l|c|c|c|}
\hline \multicolumn{1}{|c|}{ Período } & Produtos Básicos & Produtos Semimanufaturados & Produtos Manufaturados \\
\hline 2000 & $23,4 \%$ & $15,9 \%$ & $60,7 \%$ \\
\hline 2005 & $29,9 \%$ & $13,8 \%$ & $56,3 \%$ \\
\hline 2008 & $37,9 \%$ & $14,0 \%$ & $48,1 \%$ \\
\hline 2013 & $48,2 \%$ & $12,9 \%$ & $38,9 \%$ \\
\hline Variação (p.p.) 2013/2000 & $\mathbf{+ 2 4 , 8}$ & $\mathbf{- 3 , 0}$ & $\mathbf{- 2 1 , 8}$ \\
\hline
\end{tabular}

Fonte: Secex/MDIC.

As exportações nacionais na década de 2000 foram ancoradas pelo comportamento do preço das commodities exportadas pelo país. Se observarmos a evolução dos Termos de Troca das exportações brasileiras e a evolução dos preços dos produtos básicos exportados, notaremos a correlação significativa entre as duas variáveis. $\mathrm{Ou}$ seja, a evolução dos preços das commodities exportadas pelo país determinou, em grande parte, o ganho dos Termos de Troca do total exportado pelo Brasil no período recente.

A expressiva evolução positiva dos preços das commodities exportadas pelo Brasil tende a gerar impactos diversos na economia interna. É nesse contexto que surge a discussão dos impactos da perda de participação dos produtos industrializados, tanto para o consumo interno como nas exportações, fenômeno mais conhecido como desindustrialização ${ }^{3}$.

2 Uma análise detalhada sobre o comportamento altista dos preços de exportação dos produtos básicos pode ser encontrada em Markwald e Ribeiro (2005).

3 Para maiores informações sobre o tema, ver, por exemplo, Bonelli e Pessôa (2010). 
Gráfico 3 - Evolução dos termos de troca versus preços de exportação de produtos básicos (base $100=2006$ )

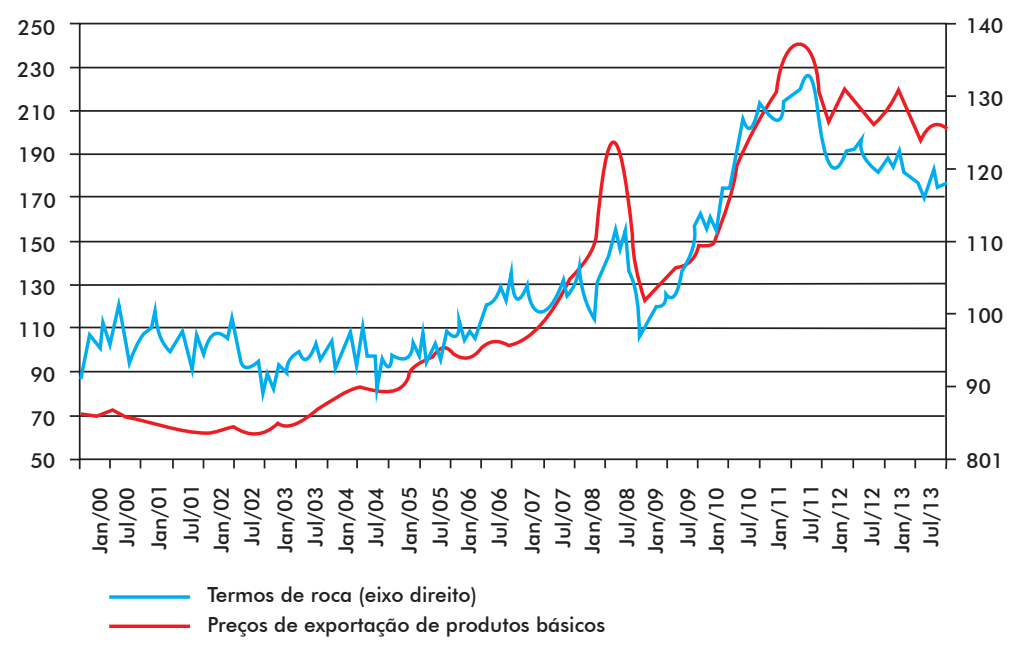

Fonte: Funcex.

Além disso, dado o ganho de participação no total produzido pelo país e, de forma mais intensa, nas exportações, torna-se importante a análise do comportamento das commodities produzidas internamente em relação à taxa de câmbio em virtude da possível correlação que possa surgir entre os caminhos percorridos pelas duas variáveis. $\mathrm{O}$ maior ganho obtido com as exportações de commodities poderia gerar uma moeda mais valorizada, em face dos ganhos obtidos no exterior e posterior internalização de recursos advindos da venda de tais produtos.

\section{A INFLUÊNCIA DA TAXA DE CÂMBIO REAL E NOMINAL DIANTE DAS COTAÇÕES DE COMMODITIES}

Em trabalhos anteriores sobre o tema (KOHLSCHEEN, 2010; CASHIN et al., 2004), destaca-se que em casos nos quais as taxas de câmbio nominal e real percorrem trajetórias sensivelmente diferentes, tal característica pode reduzir o efeito dos preços internacionais das commodities sobre o câmbio de determinado país. Como dito por Kohlscheen (2010, p. 14):

Since the real exchange rate is clearly affected by the nominal rate, it may well be that a country's currency over a given time period may not show the characteristics of a commodity currency simply because it is not allowed to fluctuate like a commodity currency in a world with price rigidities. 
Em determinado país com uma taxa de inflação relevante, as trajetórias percorridas pelo câmbio nominal e real serão significativamente diferentes. No caso brasileiro, no período recente analisado, a diferença entre a evolução do câmbio nominal e real é marcante, conforme podemos observar no gráfico a seguir.

Gráfico 4 - Taxas de câmbio nominal e real

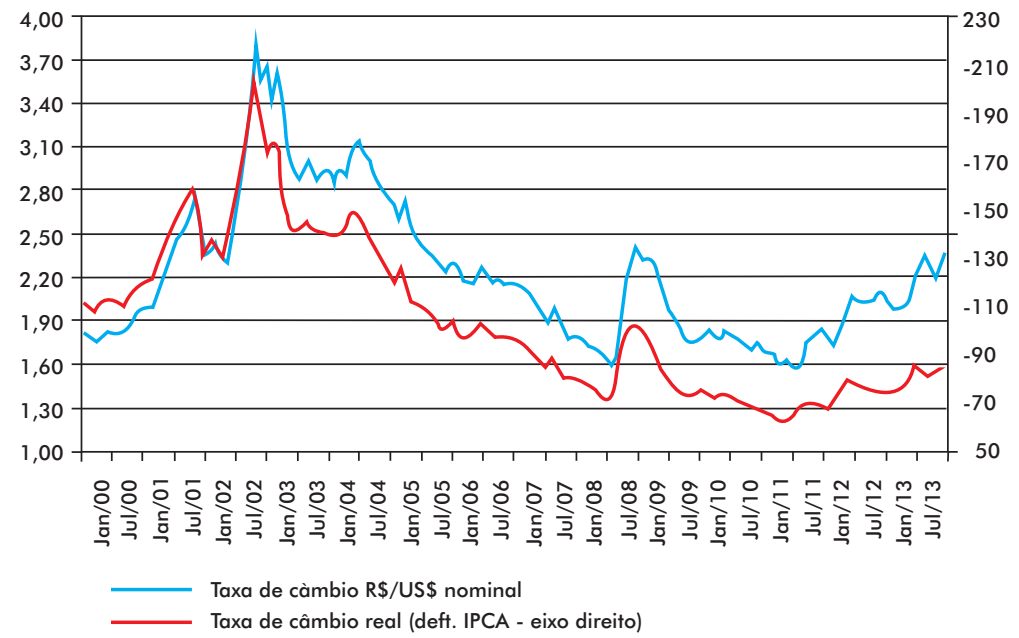

Nota: A taxa é deflacionada pelo IPCA.

Fonte: $B C B$.

Há um descolamento das trajetórias entre o câmbio nominal e real principalmente a partir de 2002, ano em que a taxa de inflação registrada foi elevada (11,9\%, pelo IPCA do IBGE). Desde então, as trajetórias têm demonstrado uma diferença constante. Entretanto, a partir de meados de 2011, a taxa de câmbio nominal apresenta uma tendência de elevação, enquanto o câmbio real não exibe o mesmo comportamento. Novamente, isso ocorre em virtude do aumento dos níveis de inflação registrados a partir de 2011 em relação ao período imediatamente anterior.

Tal fato, ainda segundo a literatura, pode dificultar a demonstração de que os preços das commodities seriam determinantes da evolução da taxa de câmbio. O descasamento das trajetórias do câmbio nominal e real poderia provocar a redução do efeito dos preços das commodities sobre o câmbio brasileiro. Contudo, realizaremos exercícios econométricos neste trabalho que levem em conta tal efeito, com o intuito de esclarecer essa nuance no caso brasileiro. 


\section{COMMODITY CURRENCIES}

Linhas de pesquisa recentes ${ }^{4}$ têm ressaltado a relação entre exportação de commodities e taxa de câmbio. A ideia básica é a de que países que são grandes exportadores de commodities tendem a ter suas moedas supervalorizadas, ou seja, mais valorizadas do que seria sua taxa de câmbio "de equilíbrio" quando ocorrem elevações nos preços das commodities produzidas por eles. Quanto maior for a participação das commodities na produção interna da economia e quanto mais altos forem os preços de tais produtos que determinado país exporte em grande quantidade, mais a moeda nacional será valorizada diante das divisas internacionais.

Comprovada essa correlação, as moedas desses países são chamadas de commodity currencies. Nesse caso, a volatilidade dos preços das commodities é transferida para as taxas de câmbio, provocando movimentos de valorização ou desvalorização que trazem prejuízos ao crescimento e à estabilidade macroeconômica.

Os modelos econométricos que analisam o comportamento do comércio exterior de um país pertencente ao modelo de commodity currencies passaram, então, a incorporar uma variável que explicitasse o comportamento dos preços das commodities. A significância existente dessa variável nos modelos destaca a importância deste grupo de bens naquela economia, dizendo se o câmbio é de fato influenciado pelo índice de preços de commodities ou não.

No Brasil, ainda não há estudos que caracterizem a moeda brasileira como uma commodity currency. No entanto, há indícios de que isso seja verdade em virtude das características apresentadas pelo perfil exportador recente do país, concentrado na venda de commodities ao mercado externo, conforme dito anteriormente.

O forte aumento do peso das commodities na pauta de exportação e a relevância da evolução dos preços na determinação do crescimento recente dos montantes exportados são características que indicam a classificação do Brasil hoje no grupo de países em que o câmbio é influenciado pela evolução dos preços das commodities, no modelo de commodity currencies.

Pode se notar um nível significativo na correlação entre a taxa de câmbio brasileira e as cotações internacionais de preços de commodities, coletadas dos dados obtidos pelo FMI, no período recente. Entre os anos 2000 e 2013, a correlação negativa entre as duas variáveis é de $64 \%$, indicando que as trajetórias do Real brasileiro sobre o dólar e os preços externos das commodities são significativas. Com o aumento observado nos preços de tais produtos, a taxa de câmbio real/dólar — opostamente - teve o viés de baixa, como pode ser observado no gráfico a seguir.

4 Por exemplo, Chen e Rogoff (2002), Fernandez (2003) e Clemens e Fry (2006). 


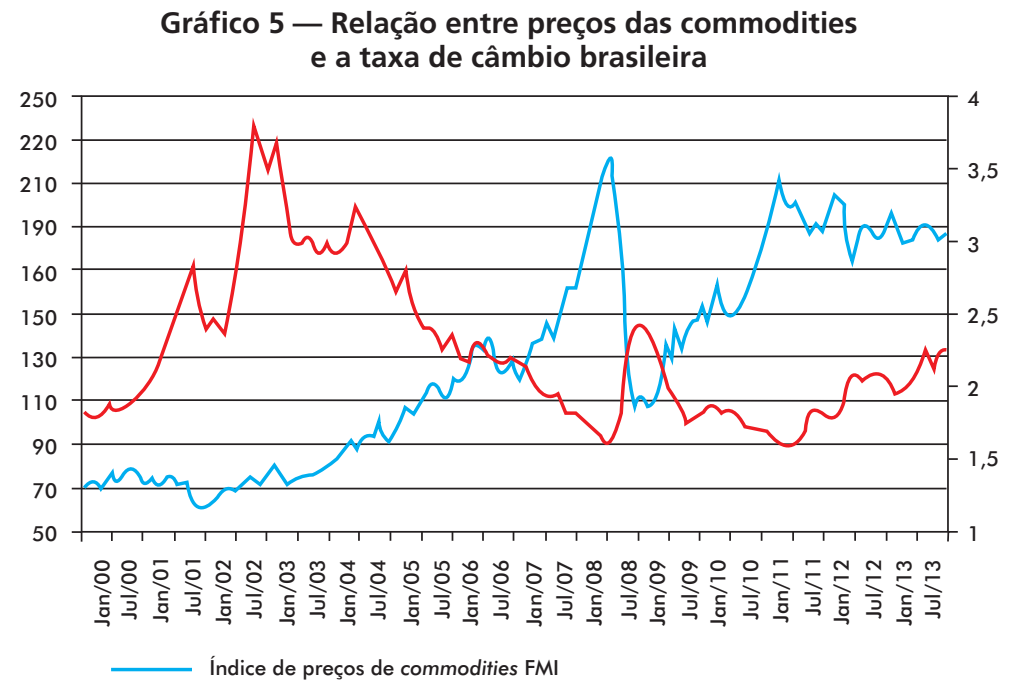

Fonte: Elaboração própria com base em dados de BCB e FMI.

Contudo, mesmo havendo a correlação negativa entre as variáveis, pode-se observar que tal comportamento não é claro para todo o período observado. Os subperíodos mais destacados em que essa relação inversa não é clara ocorrem em meados de 2008 e ao final de 2011, quando o a taxa de câmbio brasileira não segue de forma simétrica a trajetória dos preços de commodities.

\section{Gráfico 6 - Relação entre câmbio e o índice de preços de exportação de produtos básicos}

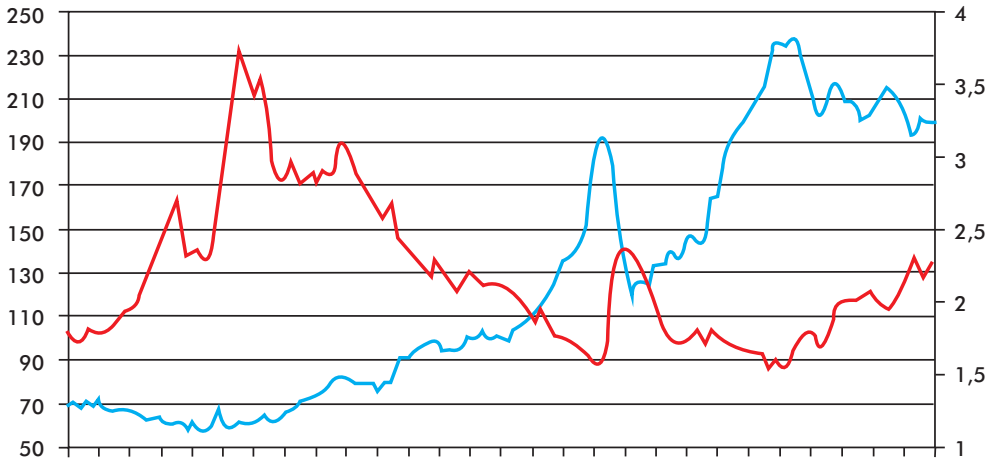

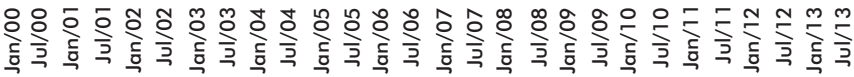

Preços de exportação de básicos

Câmbio nominal (eixo direito)

Fonte: Elaboração própria com base em dados de BCB e Funcex. 
Se utilizarmos o índice de preços de exportação de produtos básicos fornecido pela Funcex como proxy para os preços de commodities, o comportamento observado é similar à correlação do câmbio com os preços externos das commodities fornecidos pelo FMI. Ou seja, mesmo concentrando-se em uma cesta de bens exportáveis diferente daquela utilizada pelo FMI, o resultado é semelhante. A correlação também é negativa e da ordem de $61 \%$ entre as evoluções das duas variáveis.

Por sua vez, a descontinuidade da correlação entre a taxa de câmbio brasileiro e a evolução dos preços das commodities, observada em diferentes períodos, pode justificar a não caracterização da moeda brasileira como uma commodity currency por definição.

Para dar sustentação a esse argumento, podemos elencar algumas características da economia brasileira que a diferencia das demais que se encaixam no modelo de commodity currencies e que justificariam a indeterminação da relação entre o câmbio brasileiro e os preços das commodities, como segue:

1. O Brasil possui uma economia interna de tamanho significativo, com grande mercado consumidor, ao contrário da maioria dos países onde as moedas nacionais são identificadas como pertencentes ao grupo de commodity currencies (como Chile, Austrália, Argentina, etc.);

2. A reduzida participação do comércio exterior brasileiro no seu Produto Interno Bruto (PIB), que se situa em torno de $20 \%$, ao contrário dos países citados anteriormente, poderia indicar o impacto reduzido que a venda externa de commodities teria sobre as variáveis macroeconômicas do país, como o câmbio;

3. A existência de um parque industrial diversificado, que, apesar de ter perdido espaço nas exportações e no consumo interno, ainda se mantém expressivo.

Tais argumentos podem indicar que o enquadramento do Brasil no modelo de commodity currencies não seria apropriado. De fato, a economia brasileira apresenta características próprias suficientes que a tornaria diferente das demais já referenciadas no esquema de commodity currencies.

Torna-se conveniente, portanto, uma análise empírica dos dados disponíveis a fim de investigar se há suporte para tal afirmativa. Mesmo com as interpretações já realizadas das correlações características entre as variáveis que compõem o esquema de commodity currencies para o Brasil, os exercícios econométricos poderão auxiliar na busca de uma indicação mais consistente para o enquadramento ou não do Brasil no modelo. Isso será feito mais adiante neste trabalho. 


\section{REVISÃO DA LITERATURA}

Chen e Rogoff (2003) comparam as trajetórias do câmbio de três países reconhecidos por terem elevada participação das exportações de commodities no seu produto interno: Canadá, Nova Zelândia e Austrália. As taxas de câmbio de cada um dos países citados são construídas em relação ao dólar americano, à libra inglesa e a uma cesta de divisas estrangeira relevantes sem a participação do dólar. Os resultados obtidos confirmam a correlação significativa entre a evolução dos preços internacionais das commodities com a taxa de câmbio praticada nos países supracitados. Contudo, os testes econométricos realizados no trabalho se mostram mais eficientes para Nova Zelândia e Austrália, em detrimento do Canadá.

Clements e Fry (2006) analisam a relação entre a evolução dos preços das commodities e as taxas de câmbio para Canadá, Austrália e Nova Zelândia no período entre 1975 e 2005. Além disso, examinam a relação causal inversa, quando os preços das commodities são influenciados por divisas internacionais relevantes no mercado internacional. O trabalho realiza um exercício empírico através da utilização do Filtro de Kalman e conclui que as evoluções das moedas podem influenciar mais os preços das commodities do que a relação inversa, excetuando os casos em que economias pequenas têm grande participação das commodities em sua produção.

Kohlscheen (2010) realiza uma análise baseada no efeito de pass-through das variações no câmbio para o comportamento dos preços de diversas economias. $\mathrm{O}$ artigo ressalta que em trabalhos anteriores não foi considerada a alteração dos regimes de câmbio observada nos últimos anos em diversos países, caso de grande parte dos integrantes da América Latina, e conclui que o efeito de pass-through é ameno na maioria dos casos e que o efeito ocorre de forma mais intensa em países onde a volatilidade das taxas nominais de câmbio são maiores e onde há maior homogeneidade nos produtos comercializados internacionalmente. Outra conclusão exposta no trabalho revela que, no caso de Indonésia, Tailândia e México, os resultados empíricos se mostram consistentes com o modelo de commodity currencies.

Chen e Rogoff (2012) examinam novamente a correlação entre os preços das commodities e as taxas de câmbio de Austrália, Canadá, Nova Zelândia, África do Sul e incluem o Chile, chegando a uma nova conclusão de que não somente os preços das commodities afetam a taxa de câmbio, indicada através de testes econométricos robustos, mas que a taxa real de câmbio é afetada simultaneamente em face de uma alteração relevante nos preços das commodities. Os autores concluem ainda que esse efeito se mostra simultâneo em face dos reflexos pouco significativos quando é realizada a simulação de uma variação no câmbio com a alteração nos preços de tais produtos um trimestre à frente do atual.

Chen e Lee (2014) abordam o tema de commodity currencies sob uma nova perspectiva, traçando diferentes efeitos dos preços das commodities no câmbio de países 
exportadores destes a partir das perspectivas de curto e longo prazo. Segundo os autores, o efeito de uma elevação nos preços de commodities no longo prazo pode ser maior se o país em questão reunir características específicas, como (i) um mercado financeiro aberto; (ii) baixa participação da corrente de comércio externo no PIB; (iii) taxa de câmbio nominal fixa; (iv) reduzidas reservas internacionais; (v) elevada dependência econômica da exportação de commodities e (vi) participação dominante na produção mundial da commodity relacionada.

Os autores examinam o fenômeno em 63 países, entre 1980 e 2010, e obtêm conclusões importantes, como o fato de a relação de longo prazo entre preço de commodities e câmbio estar relacionada ao mercado exportador de cada país, escolhas de política monetária e o grau de abertura - tanto comercial quanto financeira - de determinada economia.

\section{ANÁLISE EMPÍRICA}

Para investigar se a taxa de câmbio brasileira é influenciada pelo preço das commodities, é conveniente incluir outras variáveis que possam influenciar também o comportamento da moeda nacional diante das divisas externas. $\mathrm{O}$ argumento para tal afirmativa reside no fato de que as variáveis econômicas que podem afetar o câmbio de um país podem ter várias naturezas, tanto referentes ao cenário interno como ao cenário internacional.

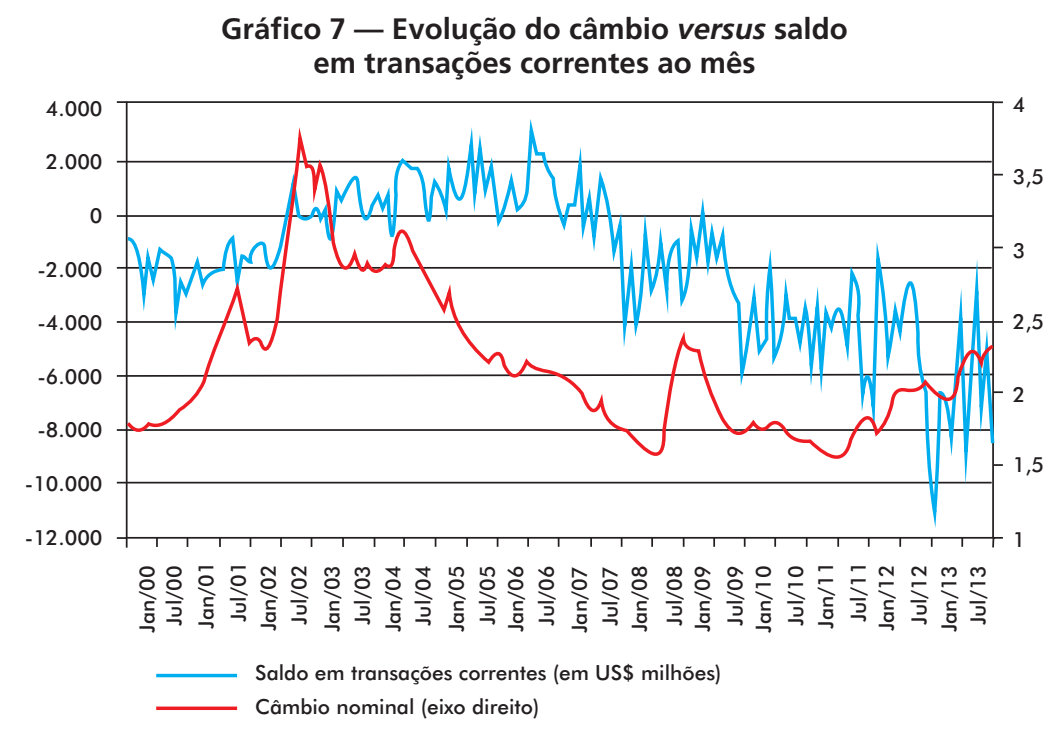

Fonte: $B C B$ 
Com o intuito de retratar esses possíveis efeitos, a inclusão de variáveis macroeconômicas relevantes para o câmbio no Brasil se torna necessária. É o caso do Saldo em Transações Correntes, variável fornecida pelo BCB que indica a soma dos resultados da balança comercial e de serviços do país.

Pode-se observar a existência de correlação entre as evoluções do câmbio brasileiro e do saldo em transações correntes. A valorização do real frente ao dólar nos últimos anos é acompanhada pela tendência de queda do saldo e a intensificação do deficit em conta corrente, que chegou a US\$ 81,1 bilhões no acumulado em 12 meses até dezembro de 2013. Portanto, a inclusão do saldo em transações correntes como variável independente a influenciar a evolução da taxa de câmbio no Brasil parece pertinente e é esperado que esta exiba significância no modelo econométrico para a investigação do real como uma commodity currency.

Na sequência, considerando a importância da indústria de transformação brasileira como componente do total produzido pelo país, a evolução do conjunto de setores que a compõem poderá influenciar também a taxa de câmbio, em grande parte em virtude da utilização de insumos importados na produção, bem como de parcela importante produzida pelo setor e vendida ao exterior. Tal efeito pode ser notado também através da correlação significativa exibida entre a evolução da taxa de câmbio e o total da produção física da indústria de transformação brasileira nos últimos anos.

\section{Gráfico 8 - Produção física da indústria de transformação versus câmbio}

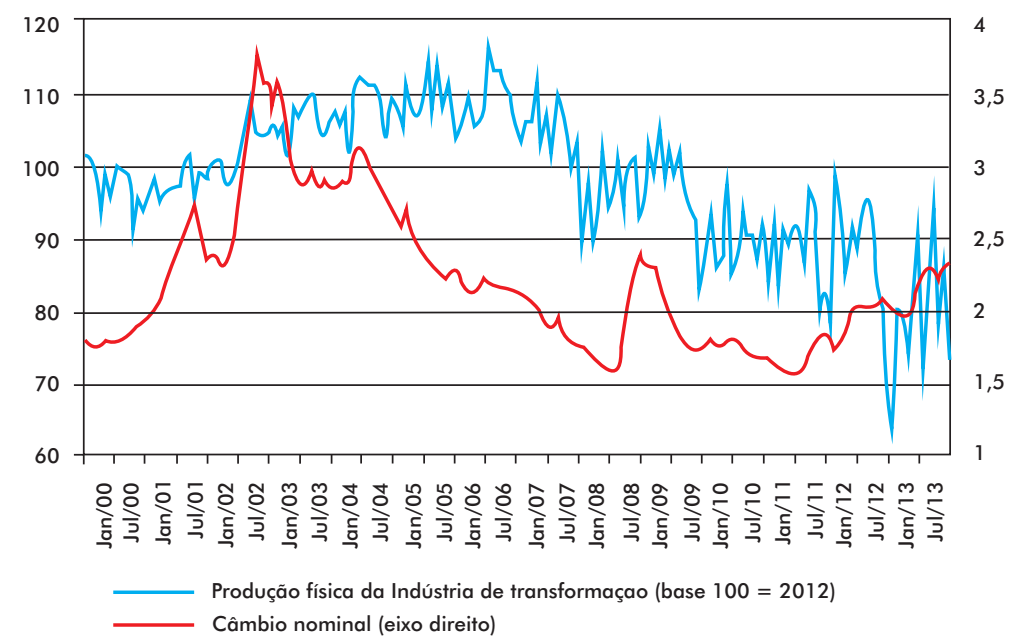

Fonte: Elaboração própria com base em dados de BCB e IBGE. 
A expressiva correlação inversa entre a produção industrial e o câmbio no Brasil evidencia a influência que a trajetória da produção industrial poderia ter sobre o câmbio. Portanto, seria conveniente integrá-la ao modelo a fim de captarmos mais esse efeito sobre a taxa de câmbio.

Apesar de os trabalhos acadêmicos relativos ao tema de commodity currencies, em geral, somente investigarem a relação entre câmbio e preços de commodities, sem a inclusão de outras variáveis, no caso brasileiro torna-se interessante incluir a evolução da indústria na mesma regressão em virtude da relevância que o parque industrial nacional ainda tem sobre o PIB brasileiro.

Da mesma forma, o saldo em transações correntes mostra-se relevante nas variações cambiais observadas nos últimos anos, em face da correlação observada entre as evoluções das variáveis e também do crescimento da contribuição externa na economia nacional.

\subsection{O MODELO}

Para reunir as possíveis inter-relações das variáveis descritas acima com a taxa de câmbio, será criada uma função para investigar empiricamente as influências destas no câmbio, conforme a função a seguir:

$$
\begin{aligned}
\ln (\text { câmbio })= & \beta_{0}+\beta_{1} \ln \text { Pcomodities }+\beta_{2} \ln \text { PordIndTransf } \\
& +\beta_{3} \ln \text { SaldoTCorr }+\varepsilon
\end{aligned}
$$

A verificação empírica da influência dos preços das commodities sobre a taxa de câmbio no Brasil é realizada por meio da modelagem de Espaço de Estados Multivariado com a estimação da Função de Verossimilhança e do Filtro de Kalman ${ }^{5}$, por meio do software Stamp (KOOPMAN et al., 2009). Os autores citados são alguns dos principais pesquisadores no campo da modelagem de Espaço de Estados, utilizando-se algoritmos calculados pelo software.

O modelo de Espaços de Estados permite decompor as séries temporais analisadas em componentes diferentes, interpretáveis com sentido econômico - como Ciclos e Tendências. Além disso, tal modelagem permite que os parâmetros estimados variem ao longo do tempo, o que representa vantagem significativa em relação a outros modelos de parâmetros fixos, como o VAR, ARIMA ou SARIMA.

\footnotetext{
Modelagem similar foi também utilizada em Clements e Fry (2006) sobre o tema.
} 
Com a representação de um modelo em Espaço de Estados, podemos utilizar algoritmos para a estimação. O Filtro de Kalman é o algoritmo mais utilizado, que realiza um procedimento recursivo para calcular o estimador ótimo do Vetor de Estados, dada toda a informação (série temporal de dados) disponível. Ao atingir o final da amostra, o algoritmo permite a obtenção do previsor ótimo das observações futuras. Os modelos estimados neste trabalho contam com a estimação através do método da Máxima Verossimilhança e da utilização do Filtro de Kalman (WELCH e BISHOP, 2006). Hamilton (1994, p. 372) define o Filtro de Kalman como:

The idea is to express a dynamic system in a particular form called the state-space representation. The Kalman filter is an algorithm for sequentially updating a linear projection for the system. Among other benefits, this algorithm a way to calculate exact finite-sample forecasts and the exact likelihood function for Gaussianarma processes, to factor matrix autocovariance-generating functions or spectral densities, and to estimate vector autorregressions with coefficients that change overtime.

Entre as diversas utilidades da modelagem, vale ressaltar a inserção de restrições em modelos multivariados (como, por exemplo, tendências comuns), bem como a verificação quanto à existência de alguma quebra estrutural ou de algum ponto espúrio na série analisada. O objetivo desse recurso é o de melhorar o ajuste do modelo através do uso de intervenções, conhecidas como variáveis dummies.

O Stamp é um software criado especificamente para a modelagem de séries de tempo a partir da utilização de componentes não observados. Os modelos de componentes não observados, ou modelos estruturais de séries de tempo, baseiam-se na decomposição clássica de uma série temporal em vários componentes, como variáveis explicativas, intervenções, variáveis endógenas defasadas, etc. Tais métodos implementados têm como base o trabalho de Harvey (1989), com desenvolvimentos mais recentes descritos em Harvey e Shephard (1993).

A vantagem na utilização do Stamp é a grande variedade de modelos que podem ser analisados, tanto univariados como multivariados. Os modelos podem incluir componentes estruturais, bem como tendências, ciclos e estados comuns e equações de séries temporais não relacionadas (MENDELSSOHN, 2011).

Tais características da modelagem escolhida se mostram interessantes para a verificação do fenômeno de commodity currencies em face da sua versatilidade e adaptação aos diferentes efeitos possíveis entre as variáveis selecionadas para a verificação da relação preços de commodities e câmbio. 


\subsection{RESULTADOS}

Após a realização da modelagem supracitada, encontramos os resultados exibidos a seguir:

\section{Modelo 1 - Variável dependente: Taxa de câmbio real}

Summary statistics

Taxa de câmbio real

$\mathrm{T} 168.00$

p 3.0000

std.error0.013261

Normality 5.5545

$\mathrm{H}(49) 0.43727$

DW1.5734

r(1) 0.21214

q 24.000

$\mathrm{r}(\mathrm{q})-0.011653$

$\mathrm{Q}(\mathrm{q}, \mathrm{q}-\mathrm{p}) 38.895$

$\mathrm{Rs}^{\wedge} 20.40413$

$\begin{array}{lllll} & \text { Coefficient } & \text { RMSE } & \text { t-value } & \text { Prob } \\ \text { Pcommodities } & -0,15493 & -0,08326 & 0,00089 & {[0,00587]} \\ \text { ProdIndTransf } & 0,05543 & 0,13771 & 0,00141 & {[0,54637} \\ \text { SaldoTCorr } & -2,79513 & -0,60460 & 0,62642 & [0,53200]]\end{array}$

Fonte: Elaboração própria com a utilização do software Oxmetrics 6.01.

Tendo a taxa de câmbio real como a variável explicada, deflacionada pelo IPCA, a regressão do Modelo 1 exibiu a variável do índice de preços de commodities como significativa em relação à taxa de câmbio ao nível de $99 \%$. O R ${ }^{2}$ ajustado apresentou resultado significativo, explicando mais de $40 \%$ do comportamento da taxa de câmbio.

O desenvolvimento do Modelo 2 busca investigar a diferença entre o comportamento da taxa de câmbio nominal da taxa de câmbio real no caso brasileiro. Conforme assinalado por Kohlscheen (2010), a taxa de câmbio de determinado país poderá ter efeitos difusos na análise em relação ao pass-through para os preços daquela economia caso os índices de inflação forem elevados, tornando as evoluções das taxas de câmbio nominal e real díspares.

Para tentarmos captar tal efeito, executamos a mesma regressão anterior, porém tendo como variável dependente o câmbio nominal. O resultado é apresentado na sequência:

Os números encontrados na regressão são, em geral, menos robustos em comparação com a regressão anterior. Contudo, da mesma forma que no modelo 1 , somente a variável referente ao índice de preços de commodities apresentou relação significativa com a taxa de câmbio. 


\section{Modelo 2 - Variável dependente: Taxa de câmbio nominal}

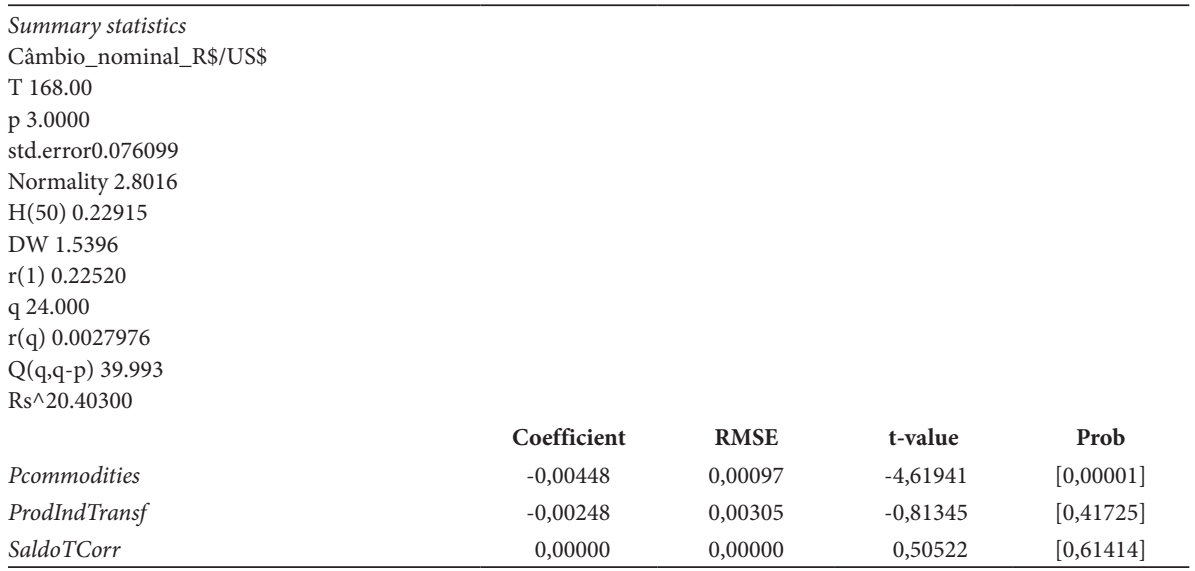

Fonte: Elaboração própria com a utilização do software Oxmetrics 6.01

A disparidade das evoluções entre a taxa de câmbio nominal e real no Brasil, de fato, ocasiona diferentes efeitos advindos da transmissão dos preços ao câmbio. Esse resultado corrobora a literatura sobre o tema, destacadamente o trabalho realizado por Kohlscheen (2010), que relata maior dificuldade no enquadramento de uma moeda como commodity currency em países onde as trajetórias do câmbio real e nominal são divergentes em face de níveis elevados de inflação.

Em suma, a importância da variação do índice de preços de commodities sobre o câmbio no Brasil se mostra relevante no período analisado, quando o Brasil se torna um importante exportador de commodities. Além disso, tais resultados exibem a importância que a produção e a exportação de commodities por parte do Brasil ganhou na economia nacional como um todo, mesmo quando defrontada com variáveis macroeconômicas importantes, como é o caso da produção física da indústria de transformação e do saldo em transações correntes.

\section{CONCLUSÃO}

Este trabalho se propôs a examinar a possível relação entre a taxa de câmbio do real brasileiro e do dólar americano com a evolução dos preços das commodities, fenômeno mais conhecido como commodity currencies. Tal relação já foi investigada em diversos países, onde as participações na produção e nas exportações desse grupo de produtos têm mostrado influência sobre suas economias como um todo, impactando diretamente na taxa de câmbio dos países que produzem e exportam diferentes bens pertencentes ao conjunto. 
Os resultados encontrados indicam que o Brasil pode estar enquadrado no modelo de commodity currencies, em virtude da correlação observada entre a evolução do índice de preços internacionais do grupo de commodities com a taxa de câmbio brasileira. Ademais, mesmo quando consideramos variáveis macroeconômicas de relevância nos testes econométricos, a influência dos preços externos das commodities mostra robustez na relação com o câmbio.

A despeito dos argumentos citados anteriormente que justificariam o não enquadramento do Brasil no esquema de commodity currencies em face de o país ter um parque industrial importante, um mercado consumidor interno de monta e uma reduzida participação do comércio exterior na economia interna - fatores que poderiam enfraquecer o efeito das exportações de commodities na economia nacional - , a influência dos preços das commodities na taxa de câmbio brasileira ocorreu de forma significativa na década de 2000 até o período recente, o que torna necessária a consideração dos impactos que tal fenômeno possa gerar nas políticas macroeconômicas adotadas pelo país.

O impacto que a inflação causa na trajetória do câmbio no Brasil também pôde ser observado nos resultados, em virtude da maior robustez destes quando se utilizou a taxa de câmbio real como variável dependente. Ao contrário, com a utilização da taxa de câmbio nominal como a variável dependente, os resultados se mostraram menos robustos, o que corrobora a literatura acerca do tema sobre os efeitos que a diferença entre as trajetórias do câmbio nominal e real têm na transmissão - pass-through dos demais preços da economia, inclusive o das commodities.

Portanto, políticas macroeconômicas praticadas pelo governo brasileiro, tanto a política cambial quanto a fiscal e a monetária, deveriam levar em consideração tal efeito do preço das commodities sobre o câmbio no Brasil a fim de obterem maior efetividade em virtude do fenômeno constatado.

Por sua vez, possíveis políticas industriais que sejam geridas pelo governo com o intuito de auxiliar a expansão da atividade industrial também deveriam levar em conta o comportamento do real brasileiro como uma commodity currrency em razão da possível ineficácia que pacotes de estímulo a setores industriais possam ter diante de tal fenômeno.

O enquadramento do real brasileiro no esquema de commodity currencies parece apropriado, em face dos dados exibidos e os resultados empíricos encontrados neste trabalho, que poderão ser analisados posteriormente em estudos adicionais a fim de propor novas metodologias para o aperfeiçoamento da análise.

\section{REFERÊNCIAS}

AVERBUG, A.; GIAMBIAGI, F. A crise brasileira de 1988/1999 — origens e consequências. Textos para discussão, IPEA, n. 77, p. 19-27, 2000. 
BONELLI, R.; PESSÔA, S. Desindustrialização no Brasil: resumo da evidência. Texto para Discussão, FGV, n. 7, 2010.

BRANCO, R. Raul Prebisch e o desenvolvimento econômico brasileiro recente liderado por commodities. Revista Sociais e Humanas, v. 26, n. 1, p. 197-216, 2013.

CASHIN, P. et al. Commodity currencies and the real exchange rate. Journal of Development Economics, n. 75, p. 239-268, 2004.

CHEN, Y. Exchange Rates and Fundamentals: evidence from Commodity Economies, Cambridge, MA: Harvard University, 2002. Mimeo.

CHEN, Y.; LEE, D. What makes a commodity currency? Working paper, University of California, Sept. 2014.

CHEN, Y.; ROGOFF, K. Commodity currencies. Journal of International Economics, v. 60, n. 1, p. 133-160, 2003.

CHEN, Y.; ROGOFF, K. Are commodity currencies an exception to the rule? Global Journal of Economics, v. 1, n. 1, 2012.

CLEMENTS, K.; FRY, R. Commodity Currencies and currency commodities. Resources Policy, v. 33, n. 2, p. 55-73, 2008.

FERNANDEZ, C. Câmbio real e preços de commodities: relação identificada através de mudança de regime cambial. Dissertação (Mestrado em Economia), Departamento de Economia, Pontifícia Universidade Católica do Rio de Janeiro, Rio de Janeiro, 2003.

HAMILTON, J. Time series analysis. New Jersey: Princeton University Press, 1994.

HARVEY, A. Forecasting, structural time series models and the Kalman filter. Cambridge, UK: Cambridge University Press, 1989.

HARVEY, A.; SHEPARD, N. Fitting nonlinear time-series models with applications to stochastic variance models. Journal of Applied Econometrics, v. 8, p. 135-152, dez. 1993.

KOHLSCHEEN, E. Emerging floaters: pass-throughs and (some) new commodity currencies. Journal of International Money and Finance, n. 29, 2010.

KOOPMAN S. et al. Stamp 8.2: Structural time series analyser, modeler, and predictor. London: Timberlake Consultants, 2009.

MARKWALD, R.; RIBEIRO, F. Análise das exportações brasileiras sob a ótica das empresas, produtos e mercados. Revista Brasileira de Comércio Exterior, n. 85, p. 3-20, 2005.

MENDELSSOHN, R. The STAMP Software for State Space Models. Journal of Statistical Software, v. 41, n. 2, 2011.

WELCH, G; BISHOP, G. An Introduction to the Kalman Filter. Chapel Hill, NC: University of North Carolina, Department of Computer Science, 2006. 